\title{
Bibliografía sobre derecho autonómico
}

$$
\text { diciembre } 2019 \text { - marzo } 2020^{*}
$$

AA.VV.: Entidades privadas colaboradoras de la administración (Dir. Alfredo Galán Galán), Ed. Tirant lo Blanch, Valencia, 2019. ISBN: 978-84-1313-588-5.

AA.VV.: Navegación de recreo y puertos deportivos: nuevos desafíos de su régimen jurídico (Dir. José Manuel Martín Osante), Ed. Marcial Pons, Madrid, 2019. ISBN: 978-84-9123-734-1.

AA,VV.: Nuevo Régimen Urbanístico de la Comunidad Valenciana. Ley 5/2014 de Ordenación del Territorio, Urbanismo y Paisaje (Coord. Jorge Hervás Más), 2ª edición, Ed. Tirant lo Blanch, Valencia, 2020. ISBN: 978-84-1336-699-9.

AA.VV.: Federalismo y Constitución (Dir. Rosa María Moreno Flórez), Ed. Dykinson, Madrid, 2020. ISBN: 978-84-1324-490-7.

AA.VV.: Los desafíos de España y Colombia en la gobernanza hídrica del siglo XXI (Dirs. Adela Romero Tarín y Lyda Teresa Córdoba Hoyos), Ed. Thomson Reuters - Aranzadi, Pamplona, 2019. ISBN: 978-84-1308-715-3.

AA.VV.: Constitución, Política y Administración: Repensando la Constitución + Guatro Décadas Después (Coord. Joaquín Martín Cubas), Ed. Tirant lo Blanch, Valencia, 2020. ISBN: 978-84-1313-796-4.

AGUDO ZAMORA, M.: Reforma constitucional y Estado Autonómico, Ed. Tecnos, Madrid, 2020. ISBN: 978-84-309-7868-7.

CANO SILVA, R.: El Estatuto del Personal de los Parlamentos Autonómicos en el Actual Sistema Español de Fuentes del Derecho, Ed. Tirant lo Blanch, Valencia, 2019. ISBN: 978-84-9190-965-1.

GUILLÉN LÓPEZ, E.: Repensando la forma de gobierno. Constitucionalismo, democracia y parlamentarismo en contextos posnacionales, Ed. Marcial Pons, Madrid, 2019. ISBN: 978-84-9123-735-8.

RANDO BURGOS, E.: Régimen jurídico de la gestión territorial, Ed. Tirant lo Blanch, Valencia, 2020. ISBN: 978-84-1313-775-9.

\footnotetext{
* Sección a cargo de Javier E. QUESADA LUMBRERAS.
} 